\title{
Book vs. Fair Value Accounting in Banking, and Intertemporal Smoothing. *
}

\author{
Xavier Freixas ${ }^{\dagger}$ and Dimitrios P. Tsomocos ${ }^{\ddagger}$
}

September 7, 2004

\begin{abstract}
The aim of this paper is to examine the pros and cons of book and fair value accounting from the perspective of the theory of banking. We consider the implications of the two accounting methods in an overlapping generations environment. As observed by Allen and Gale(1997), in an overlapping generation model, banks have a role as intergenerational connectors as they allow for intertemporal smoothing. Our main result is that when dividends depend on profits, book value ex ante dominates fair value, as it provides better intertemporal smoothing. This is in contrast with the standard view that states that, fair value yields a better allocation as it reflects the real opportunity cost of assets. Banking regulation play an important role by providing the right incentives for banks to smooth intertemporal consumption whereas market discipline improves intratemporal efficiency.
\end{abstract}

\section{Introduction}

We like to feel that, not only do the figures in the balance sheet show you the true position, but that the real position is a little better still.

W. E. Hubbard, Chairman, London and County Bank ${ }^{1}$.

The aim of this paper is to explore the effect of financial institutions accounting rules, i.e. book or fair value, on the allocation of resources so as to identify its social costs and benefits.

\footnotetext{
${ }^{*}$ We are thankful to the seminar participants at the Saïd Business School, the ECB, to Charles Goodhart and John Turner for their invaluable insights and suggestions. This paper was started while Xavier Freixas held the Deutsch Bank visiting professor chair at the Saïd Business School.

†Universitat Pompeu Fabra and CEPR

¥Saïd Business School and St. Edmund Hall, Oxford University

${ }^{1}$ In the speech of W. E. Hubbard to shareholders at the annual meeting, 7 February 1901.
} 
During the last two decades the issue whether bank assets and liabilities should be accounted for at their historical (book) value or at market (fair) value has been the object of an intense debate among regulators. In the end, fair value accounting, supported by the Joint Working Group of Standard Setters ${ }^{2}$, seems to have the upper hand. Although these points can be disputed on the basis of asymmetric information and managerial incentives to truthfully reveal information, the prevailing view is that a sufficiently high level of penalties could restore incentives for managers to report the true market values of assets and liabilities.

The case in favour of fair value accounting has been based on the idea that fair value could increase market discipline and lead managers to take the right value maximizing decisions. Yet, it has been argued that fair value accounting increases the volatility of banks profits, and this will hurt the business of banking, which is based on the long term relationship of a bank with its clients (Chisnall, 2000). Additionally, it has been argued that fair value accounting lacks accuracy as it relies on subjective proxies for the market value of nontradeable financial products (as loans). On the other hand, value accounting may help preventing systemic crises, as information on banks financial distress is obtained earlier ${ }^{3}$.

This paper takes a completely different view of the book vs. fair value accounting debate.

Our objective is not to counter this arguments but to point out that there is at least another important dimension at work, the degree of intertemporal smoothing, and that it may support the use of book value accounting. From that perspective, the main achievement of our paper is to show the dark side of the comparison and to point out that the use of fair value accounting does not dominate book value accounting in a straightforward and robust way. Moreover, if we allow for fair value disclosure, the whole argument in favour of fair value accounting seems to vanish ${ }^{4}$. Indeed, the market discipline argument is based on disclosure of the fair value of assets and liabilities, not on its effective use in accounting with its fiscal and legal implications.

The argument developed in the present paper is that bank's economic role is to allow for intertemporal smoothing. By facilitating intergenerational transfer of resources and insuring future generations consumption against risky asset returns and price fluctuations, banks improve expected welfare.

The study of the effect of accounting rules on the allocation of resources requires a model where banking activity matters, that is, banks are not redundant and their strategies have non-neutral effects.

\footnotetext{
${ }^{2}$ The Working Group comprises representaives of the accounting standard setting bodies represented on the G4+1, i.e. the United States, Canada, Australia, New Zealand and the United Kingdom, plus Germany, France, the Nordic Federation and Japan.

${ }^{3}$ See, Enria et al. 2004 for a more complete summary of the different arguments.

${ }^{4}$ Jackson and Lodge(2000) suggest this and point out that even if fair value accounting is adopted, in most countries regulatory capital includes profits only in as far as they are realized. This means that the use of fair value accounting does allow to abandon book value accounting, as the amount of unrealized profits, that corresponds to the difference between book and fair value profits will still have to be reported.
} 
In a standard static model, such as the Arrow-Debreu model, where institutions do not play a significant role, the issue of comparing different accounting rules cannot be addressed. More generally, in any situation where the Modigliani-Miller theorem holds, the value of a firm with book value and fair value accounting should be the same. So, if we want to avoid this type of shortcoming, it is worth starting by identifying the type of environments where market imperfections make the book vs. fair value accounting rule relevant and then proceed to compare their relative performance.

As a consequence, we are naturally led to develop a dynamic model of financial intermediation with active financial intermediaries whose decisions depend on the specific accounting rules adopted.

Following Allen and Gale(1997), we define a bank as an institution with the ability to smooth intertemporal shocks. This is precisely the role mutual funds cannot play. This is also related to the concept of banks as an additional security, developed in a different context by Diamond and Dybvig(1983), Jacklin(1987) and Gorton and Pennacchi(1990). Yet, in some environments, the ModiglianiMiller theorem holds and banks are redundant, and this prevents them from performing any intertemporal smoothing. In this case, banking regulation will become crucial in establishing banks as a differentiated security and ensuring the superiority of the banking system. Because of the support of regulatory institutions (access to Central Bank/Deposit Insurance Company), banks are then able to offer contracts with superior intertemporal insurance characteristics.

Our main result establishes that if asset prices follow a martingale, as it happens in an informationally efficient market, then book value accounting is preferred to fair value accounting. The main intuition for our result is related to the role of banks in the intertemporal smoothing process. Banks will provide insurance against unforeseen contingencies through their dividend policy. By building reserves during good times and depleting them during bad times, banks will be able to smooth consumption as did Pharaoh under Joseph's guidance avoiding the worst effect of the seven year drought. Yet, competition among banks may erode this role by making them focus on the current bank-owners interests, thus disregarding future generations. In this case, regulation may limit the banks shortsightedness by restricting the class of dividend rules that banks may utilize. Since asset prices are assumed to follow a martingale, fair value accounting rules lead to greater variability in profits, and therefore in dividend distribution; this in turn implies that book value accounting offers better intertemporal smoothing as dividend distribution is less variable.

It is difficult to assert which, of market discipline and intertemporal smoothing, is the dominant force, and, of course, clearly beyond the scope of our paper. Our contribution is simply to emphasize intertemporal smoothing and why it matters in the choice of an accounting system.

In a world with heterogenous competitive banks, accounting rules may have different effects on how information is disseminated and used by investors in their decisions, and this may have an impact on the resulting allocation.

The current debate of book vs. fair value accounting is reminiscent of the debate on hidden reserves held by banks in the 60's in the U.K,.where banks were 
exemplt from full disclosure of profits. Indeed, the Company Law Committee under Lord Jenkins assessed this exemption and recommended its continuation in 1962. The basic argument for this recommendation was that this exemption permitted the banking sector to absorb adverse shocks more effectively and thereby preserve its stability. It was suggested that full disclosure would not necessarily mitigate the impact of shocks but instead could generate contagious effects to the rest of the banking sector in international financial centres such as London. On the other hand, banks in U.S.A. were obliged to publish operating accounts during that period on the grounds that fragility could be corrected more easily if it became common knowledge to all investors. More recently, hidden reserves maintained by German banks have allowed them to deal more effectively with negative shocks to their balance sheets.

In sum, hidden reserves in the past and book vs. fair value accounting today underscore similar insights and address quite related issues in banking.

The structure of our paper is the following: in Section 2 we present a standard (overlapping generation model, OLG) model with banks as intergenerational connectors and equilibrium is calculated for the corresponding market economy. We establish that the regulated banking mechanism ex ante dominates the market economy allocation. We proceed in Section 3 to define a class of dividend rules and how they are modified by the two different accounting schemes we consider, thus providing our main result. Section 4 addresses the issue of fair value accounting as related to transparency and disclosure with its beneficial impact on intertemporal efficiency. Section 5 concludes and considers potential extensions of the model.

\section{Banks as intergenerational connectors}

We consider a standard two-period OLG model without production. Time is divided into a countably infinite number of dates, $t=0,1, \ldots$. A new generation is born at each date $t$ and lives for two periods. It consists of identical consumers and at time $t=0$ there is an initial old generation that lives for only one period has no endowment but owns all the assets in the economy. There is a single consumption good and the initial endowment of each generation $e_{t}$ is received when it is young ${ }^{5}$. This precludes borrowing.

There exists two technologies, one storage and one risky.

The storage technology is riskless and yields a zero return.

The risky asset is in limited supply and yields a stochastic return $\widetilde{y}_{t}, E\left(\widetilde{y}_{t}\right)>$ 0 , which is i.i.d. We assume that $\widetilde{y}_{t} \geq 0$. Because this return is higher than zero, the risky asset will dominate the storage technology, provided price fluctuations are bounded, which we will initially assume. Furthermore, the risky asset is perfectly durable. The riskless and risky assets are used to provide for consumption in future dates and cannot be sold short.

\footnotetext{
${ }^{5}$ Formally, the endowment vector is denoted $\left(e_{1 t}, e_{2 t}\right), \forall t$. Since, the old generation does not receive any endowment we suppress the generation index.
} 
We will also introduce a financial intermediary which may be a mutual fund or a bank whose role is that of an intergenerational connector between generations. This financial intermediary may be implemented by the first generation, that is, the old generation at time $t=0$. If so, every young generation will invest in the bank's equity the amount $s_{t}$ and this will be transferred to the next generation. The bank buys a portfolio of the riskless and risky assets (technologies), and issues deposit contracts at an interest rate $r_{d}$. Also, the bank distributes dividends according to some pre-specified rule $D_{t}$ at each date $t \in T$. These dividends are contingent as they depend upon the "state of nature" and in particular on the bank profits which are computed either using a book value or a fair value accounting rule.

In order to define a well specified framework, we introduce the following notations:

$c_{i t}=$ consumption at period $i=1,2$ of the generation born at $t$,

$x_{t}=$ amount of risky assets purchased,

$s_{t}=$ amount of bank equity purchased by the young generation (sold by the old generation)

$d_{t}=$ deposits at time $t$,

$p_{t}=$ risky asset price at $t$, and

$q_{t}=$ bank's equity prices at $t$.

We assume that the time-separable utilities $u(), v()$ are monotonic, strictly concave and satisfy the Inada conditions. In what follows we will take $u()=$ $v()=\log ()$. This will allow us to simplify the dynamic structure of prices and find simple solutions to the dynamic recursive equations.

We normalize commodity prices to 1 .

$$
\begin{aligned}
& \max E\left\{u\left(c_{1 t}\right)+v\left(c_{2 t}\right)\right\} \\
& c_{1 t}+p_{t} x_{t}+d_{t}+s_{t} q_{t} \leq e_{t} \\
& c_{2 t} \leq\left(p_{t+1}+y_{t}\right) x_{t}+d_{t}\left(1+r_{d}\right)+s_{t}\left(q_{t+1}+D_{t}\right)
\end{aligned}
$$

Because in equilibrium both constraints are binding, we are allowed to substitute the values of the consumption, $\left(c_{1 t}, c_{2 t}\right)$. The problem is then to choose the amount of assets $\left(x_{t}, d_{t}, s_{t}\right)$ that solves

$\max u\left(e_{t}-\left(p_{t} x_{t}+d_{t}+s_{t} q_{t}\right)\right)+E\left\{v\left(\left(p_{t+1}+y_{t}\right) x_{t}+d_{t}\left(1+r_{d}\right)+s_{t}\left(q_{t+1}+D_{t}\right)\right)\right\}$

The first order conditions are:

$$
\begin{aligned}
-u^{\prime}\left(c_{1 t}\right) p_{t}+E\left[v^{\prime}\left(c_{2 t}\right)\left(p_{t+1}+y_{t}\right)\right] & =0 \\
-u^{\prime}\left(c_{1 t}\right)+\left(1+r_{d}\right) E\left[v^{\prime}\left(c_{2 t}\right)\right] & =0 \\
-u^{\prime}\left(c_{1 t}\right) q_{t}+E\left[v^{\prime}\left(c_{2 t}\right)\left(q_{t+1}+D_{t}\right)\right] & =0
\end{aligned}
$$


These conditions can be reinterpreted in terms of risk and return. If we denote the net rate of return on the risky asset and on the bank's stock by $r_{x}$ and $r_{s}$ respectively, the above equalities imply:

$$
\begin{aligned}
& E\left(r_{x}\right)=r_{d}+\frac{-\operatorname{cov}\left(v^{\prime}\left(c_{2 t}\right), r_{x}\right)}{E\left(v^{\prime}\left(c_{2 t}\right)\right)} \\
& E\left(r_{s}\right)=r_{d}+\frac{-\operatorname{cov}\left(v^{\prime}\left(c_{2 t}\right), r_{s}\right)}{E\left(v^{\prime}\left(c_{2 t}\right)\right)}
\end{aligned}
$$

This allows us to establish that, as expected, because of the positive covariance between $c_{2 t}$ and $r_{s}$, the concavity of $v$ implies that there is a positive risk premium, that depends upon the covariance of the marginal utility of consumption with the return of the asset.

We will now proceed to compare the allocation resulting from a market economy and the one generated by a banking economy.

\subsection{Equilibrium in a market economy}

To begin with, consider a market economy. Markets are incomplete for two reasons: on the one hand, short sales are not allowed and on the other hand each generation is only able to contract with the succeeding one.

At each period the old generation owns the risky asset and will sell it to the next one when they are young.

An equilibrium consists of a sequence of prices, portfolios and consumption bundles such that agents optimize their consumption and saving subject to their budget constraints and markets clear.

Formally, an equilibrium will be described as a sequence $\left(p_{t}, q_{t}, s_{t}, c_{1 t}, c_{2 t}, d_{t}, r_{d}\right)$ such that:

1. $c_{1 t}, c_{2 t}, x_{t}, s_{t}$ is optimally chosen by consumers, so that it solves (1)

2. $c_{1 t}+c_{2 t-1}=e_{t}+y_{t} \quad t=1,2, \ldots$

3. $x_{t}=1$

4. $s_{t}=1$

Condition 2, 3 and 4 are market clearing conditions respectively for the consumption good, the risky asset and the bank equity, where the supply of the risky asset and of the bank equity is fixed and normalized to one.

Furthermore, an equilibrium is a stationary Markov equilibrium only if $\left\{\left(p_{t}, q_{t}\right) ;\left(c_{1 t}, c_{2 t}, d_{t}, x_{t}\right)\right\}=f\left(\widetilde{y}_{t}\right), \forall t \in T$.

In other words, in a stationary Markov equilibrium the equilibrium variables are related to the stochastic process $\left(\widetilde{y}_{t}\right)_{t \in T}$ in a time-invariant way.

Expression (1) is then simplified as

$$
\max u\left(e_{t}-p_{t} x_{t}\right)+E\left\{v\left(\left(p_{t+1}+y_{t+1}\right) x_{t}\right)\right\}
$$


In equilibrium, the first order conditions will be satisfied for $x_{t}=1$, as the representative consumer demands the whole available supply of the risky asset.

$$
u^{\prime}\left(e_{t}-p_{t}\right) p_{t}=E\left\{v^{\prime}\left(p_{t+1}+y_{t+1}\right)\left(p_{t+1}+y_{t+1}\right)\right\}
$$

This yields the price $p_{t}$ as a function of the distribution of future prices $p_{t+1}$.

For the logarithmic utilities case, the right hand side in (3) equals one and the first order condition simplifies to

$$
\frac{p_{t}}{e_{t}-p_{t}}=1
$$

yielding $p_{t}=\frac{e_{t}}{2}$.

The fact that the risky asset dominates the storage one implies that the corresponding contingent consumption path of generation $t$ is therefore,

$$
\begin{aligned}
c_{1 t} & =\frac{e_{t}}{2}, \text { and } \\
c_{2 t} & =\frac{e_{t+1}}{2}+y_{t+1} .
\end{aligned}
$$

Thus, in a market, the old generation has a higher expected consumption and bears all the market risk embodied in the $y_{t+1}$ random variable.

In addition, as it is obvious from the above expressions, in a market economy, consumption depends exclusively on endowments and on contemporaneous asset yields. There are no reserves to provide any smoothing and the expected consumption is unbalanced, as it is larger in the second period. This inefficiency is caused by the short-selling restriction and the fact that each generation contracts only with the succeeding one.

\subsection{Banking economy}

When a bank exists, it holds the risky asset which is not traded among consumers. The bank will therefore be a portfolio of cash $M_{t}$ and of stocks $x_{t}^{B}$ with deposits $d_{t}$ remunerated at rate $r_{d}$ and a dividend distribution rule $D_{t}$. The bank is initially owned by the first generation, i.e. the old at $t=0$.

Without loss of generality we will set deposits at the level $d_{t}=0$, for every $t$ and assume that the dividend is the total remuneration on the portfolio of deposits and bank equity shares the consumer holds.

Expression 1 simplifies to

$$
\max u\left(e_{t}-s_{t} q_{t}\right)+E\left\{v\left(s_{t}\left(q_{t+1}+D_{t}\right)\right)\right\}
$$

The first order conditions are then

$$
u^{\prime}\left(e_{t}-q_{t}\right) q_{t}=E\left\{v^{\prime}\left(q_{t+1}+D_{t}\right)\left(q_{t+1}+D_{t}\right)\right\}
$$


In the logarithmic case this implies

$$
q_{t}=\frac{e_{t}}{2}
$$

and the corresponding consumption path is

$$
\begin{aligned}
c_{1 t} & =\frac{e_{t}}{2} \\
c_{2 t} & =\frac{e_{t+1}}{2}+D_{t}
\end{aligned}
$$

Notice that as before the old generation has a higher expected consumption. Nevertheless the dividend rule allows to smooth (or to exacerbate) the distribution of the risky security return $\widetilde{y}_{t+1}$.

As a consequence, the creation of a bank affects the future generations consumption.

Three remarks are in order to clarify the role of banks and their impact on allocation.

First, notice that we have obtained this result assuming that consumers cannot invest directly in the risky asset. If we assume consumers are able to invest in both the asset and the bank shares, then arbitrage between the two assets will allow the Modigliani-Miller theorem to hold and the bank dividend policy will be irrelevant.

The following Lemma establishes that this will occur for a finite horizon $T$. Therefore, if we take the limit as $T$ goes to infinity we will obtain a solution where Modigliani-Miller theorem will hold.

Lemma 1 : In a finite horizon, if consumers have access to both the risky asset and the bank shares, the value of a bank is independent of its dividend policy.

Proof. See the Mathematical Appendix.

This result establishes that when consumers have the same investment possibilities as the bank, any attempt to provide intertemporal smoothing through the dividend policy will have an immediate effect on the price of the bank asset and this will make it ineffective. In this context, there is no difference between a bank and a mutual fund, and the bank is redundant.

This result is not entirely surprising as the same effect occurs in Diamond and Dybvig: once agents have access to a market at an interim period the provision of liquidity insurance by the bank is no longer possible. In both cases are able to play the market against the bank contract, and this destroys any insurance.

Notice that banking regulation could nevertheless provide intertemporal smoothing, thus allowing the bank to design assets that a consumer cannot access. So, for instance by providing deposit insurance, a regulated banking economy could provide some degree of intertemporal smoothing. However, credit enhancement can only be provided to the economy by an outside institution. 
This is the case since the young generation has a higher endowment than the old one.

A second remark concerns the processes of banks creation. Because the degree of intertemporal smoothing depends on the reserves the banks have built, it is clear that the first generations will not benefit from intertemporal insurance. Consequently, the first generation will never voluntarily set up a bank, except if the price of the bank is higher than the value of the bank portfolio (as future generations value the dividend smoothing services). In the logarithmic case this is not true and therefore the banking system will be created either with a subsidy to the first generation or by coercing it to accept the bank. In any case, our model points that the creation of an intertemporal smoothing banking system goes hand in hand with the introduction of regulation.

A third remark concerns competition and the banks objective function. If the banking system consist of several competing banks, they will compete each period for new costumers. As a consequence, they will design their dividend policy in order to attract the next generation. Since competition will start with the first generation, competing banks will promise the highest possible return, and commit to pay a dividend equal to $x_{t}^{B} y_{t}$. Consequently, the bank will never accumulate resources and this leads to the following Lemma.

Lemma 2 : In a competitive banking system the banks' dividend policy is to pay the full amount of its profit, $x_{t}^{B} y_{t}$, thus providing the same allocation as the market economy.

Proof. To see why, consider in the logarithmic case two banks with equal market shares and equal dividend rules. The equilibrium stock prices $q_{t}=$ $\frac{e_{t}}{2}$ would be for both banks. If banks were offering a dividend lower than $x_{t}^{B} y_{t}$, a deviating bank offering a higher dividend would provide a higher level of consumption at period $t=2$, thus attracting all demand.

\subsection{Comparison}

The next natural step is to examine the efficiency properties of equilibrium. For this purpose, we adopt the point of view of the ex ante design of the allocation mechanism. This means that customers do not know initially in which generation they will live and therefore the objective is to maximize the expected average utility. As it is well known, an ex ante efficiency allocation need not be ex post efficient. In the present framework, since any intertemporally smooth dividend rule involves "taxing" the first generations where the good state of nature is realized, the bank economy is not ex post Pareto efficient. This concept of welfare analysis is in contrast with the classical ex post Pareto optimality result derived in Samuelson(1957) .

One might expect, since the safe asset market is inactive, that markets are complete and therefore equilibrium is efficient. However, as the unborn agents cannot invest (i.e. restricted participation) or alternatively because each generation lives for only two periods and thus longer investments are not possible, market incompleteness is maintained. 
Banks are able to build stores of reserves and deplete them. The way in which they do so depends on their dividend policy. We will postulate that their policy is to provide intertemporal smoothing. This is done by distributing a low dividend in good times and a high one in bad times. Notice that this is precisely the opposite of the policy required to preserve capital. The preservation of capital would imply the distribution of a low dividend in bad times and the distribution of a high dividend in good times. The difference between the two types of dividend rules comes from a difference in the objectives, as capital regulation is aimed at limiting banks bankruptcies while our approach, maximizes the ex ante representative consumer overall welfare. Put differently, we note the existence of a trade off between financial stability and efficiency.

To be more precise we state the following definition

Definition 1: A series $w_{t}$ is intertemporally smoothing with respect to $z_{t}$ over a horizon $T$ if for every event $\omega \in \Omega, z_{t}$ is a mean preserving spread of $w_{t}$, that is, it satisfies $\sum_{\tau=0}^{\tau=t} z_{\tau} \geq \sum_{\tau=0}^{\tau=t} w_{\tau}$ with equality for $t=T$.

Definition 2: A series $w_{t}$ is intertemporally smoothing with respect to $z_{t}$ if for every $T, T \geq T^{\prime}$, the series $w_{t}^{\prime}$ is intertemporally smoothing with respect to $z_{t}$ over a horizon $T$, where $w_{t}^{\prime}=w_{t}$ for $t \leq T-1, w_{T}^{\prime}=\sum_{\tau=0}^{\tau=T} z_{\tau}-\sum_{\tau=0}^{\tau=T-1} w_{\tau}$.

$w_{t}^{\prime}$ is the amount invested in the storage economy.

Notice that the first $T^{\prime}$ periods are irrelevant for this definition.

Lemma 3 : If $w_{t}$ is a mean preserving spread of $z_{t}$ over a horizon $T$ then $\sum_{\tau=0}^{\tau=T} v\left(z_{t}\right) \geq \sum_{\tau=0}^{\tau=T} v\left(w_{t}\right)$ for any concave function $v()$.

Proof. We apply the Rothschild-Stiglitz result not to the original probability distribution but simply to the resulting random drawing. For any given event $\omega \in \Omega$, we are applying the Rothschild-Stiglitz theorem to the resulting distribution over a horizon $T$ with equal probabilities $\frac{1}{T}$. This implies that for any concave function $v()$ we have $\frac{1}{T} \sum v\left(z_{t}\right) \geq \frac{1}{T} \sum v\left(w_{t}\right)$. Since this is true for every $T$, in the limit the inequality is preserved.

Application of the lemma to the consumption series for $c_{2 t}$ in a market and a banking economy leads to the following result.

Proposition 1: The bank economy allocation is ex ante Pareto superior to the market allocation for any intertemporal smoothing dividend rule.

Proof. Let $\left(c_{1 t}^{M}, c_{2 t}^{M}\right)$ and $\left(c_{1 t}^{B}, c_{2 t}^{B}\right)$ be the corresponding consumption plans of the market and the banking economy respectively. $c_{1 t}^{M}=c_{1 t}^{B}$ and $D_{t}$ is intertemporally smoothing with respect to $y_{t}$. By lemma $3, E\left\{u\left(c_{1 t}^{M}\right)+v\left(c_{2 t}^{M}\right\} \leq\right.$ $E\left\{u\left(c_{1 t}^{B}\right)+v\left(c_{2 t}^{B}\right\}\right.$

The upshot of the argument is that a mutual fund financial intermediary does not suffice to implement a pareto improving equilibrium. The reason is that for intertemporal smoothing to occur a more complex type of contingent contract, and therefore a more sophisticated banking structure is needed. 
As it is well known, OLG models produce inefficient outcomes. Bloise and Polemarchakis(2004) argue that this inefficiency can be removed as long as there exists an "outside agent" of finite measure that facilitates transfers or resources across generations. In our case, the role of this "outside agent" is played by the banking system. Put differently, since markets are incomplete, the introduction of a banking system increases the future contingencies for which insurance contracts are available (i.e. the span of the traded assets increase). However, the introduction of the new assets needs to be carefully chosen since any new asset does not necessarily improve the equilibrium outcome.

\subsection{Safety net and intertemporal smoothing}

Proposition 1 shows how an infinitely lived bank can provide intertemporal smoothing through the dividends it pays. Still, the degree of smoothing will depend on whether there are other mechanisms to provide additional insurance. These mechanisms are part of the safety net of the banking system, and basically provide the bank with an external insurance mechanism in order to design a security the market cannot create that involves a higher degree of intertemporal smoothing. Whether this is obtained through bail-outs, subsidies, nationalization or deposit insurance is irrelevant in the present context. In any case, the creation of a safety net increases the degree of intertemporal smoothing and improves the resulting allocation.

To illustrate our point, we will consider the two extreme cases regarding the safety net. In the first one, the bank is insured against all possible risks. In the second one, the regulator provides no insurance whatsoever.

1. If the safety net allows to insure against any risk, the bank will be fully insured and first best ex ante optimality will be achieved. The bank need not have any capital and will pay their depositors a rate equal to $E\left(y_{t}\right)$. All generations will then be fully insured against the random return $y_{t}$. When the bank's reserves are depleted, the Government or the Deposit Insurance Company will inject the necessary funds in the bank. When the bank is successful it will either accumulate reserves or repay its debt to the (external) insurer. Note that this mechanism satisfies the Government or the Deposit Insurance Company's budget constraints so it is self-financing in expected terms.

2. The opposite case occurs when there is no safety net. In this case, only internal insurance through building of reserves is available, and the first generations have to decrease their consumption in order to provide insurance to the future ones. For example, this occurs if the first realization is a bad one. With some probability these reserves go back to zero after a series of unlucky realizations of $y_{t}$ and the next generations will have to decrease their consumption again.

Intertemporal smoothing is perfect in case one where all the risks of the banking sector are borne by the Treasury. This perfect insurance of the banking 
sector by the Treasury may turn out to be infeasible or to involve too high a cost. On the other hand, it is seldom the case that the Government provides no safety net to the banking sector as occurs in case 2 . So, we will focus on the case of a limited safety net. Although we do not model it explicitely, notice that this framework allows to determine the optimal size of the safety net by comparing the benefits of insurance and the costs of banks bail-outs. This is done independently of any reference to managers excessive risk taking and absence of market discipline. We hasten to remark that the presence of a safety net, although self financing in expected terms, requires the institution which implements it to be able to violate its period-by-period budget constraint when needed ${ }^{6}$.

Assume the safety net mechanism is deposit insurance. Then, limited insurance implies that there is a maximum level of deposits the bank is able to raise, $d_{t} \leq \bar{d}$ and in our model this is tantamount to imposing a minimum capital requirement.

The bank will set at time $t=0$ a dividend rule $D_{t}$. With some probability the bank will go bankrupt and the deposit insurance company will inject additional funds which it will recover in future periods. As it is obvious to regulators, the probability a bank goes bankrupt depends on the dividend rule it states, $D_{t}$. This will be important in the discussion as we will argue that the regulator may set restrictions on dividend rules, as dividend distribution reduces the bank capital.

As the bank maximizes the expected average utility of future generations it will solve

$$
\begin{aligned}
& \max \lim _{t \rightarrow \infty} \frac{1}{T} \sum_{t=0}^{\infty} E\left\{u\left(c_{1 t}\right)+v\left(c_{2 t}\right)\right\} \\
& c_{1 t}+d_{t}+q_{t}=e_{t} \\
& c_{2 t}=d_{t}\left(1+r_{d}\right)+q_{t+1}+D_{t} \\
& D_{t}=y_{t} x^{B}-r_{d} d_{t}+M_{t}-M_{t+1} \text { if positive } \\
& D_{t}=0 \text { otherwise }
\end{aligned}
$$

The solution to this program will be a function

$$
D_{t}=\phi\left(M_{t}, e_{t}, y_{t}\right)
$$

\subsection{Competition and the role of regulation}

As we have already stated in Lemma 2, competition disables the ability of banks to provide intertemporal insurance. Consequently, if the banking industry is competitive, the existence of a safety net will allow to smooth the intertemporal flow of bank payments to their claimholders.

\footnotetext{
${ }^{6}$ This argument is reminiscent of the Fiscal Theory whereby monetary policy non-neutrality is possible only if the Government budget constraint is violated.
} 
Banks will not be redundant because the safety net provides them with access to a different security. In this way the existence of a safety net allows the reconciliation of competition with intertemporal smoothing. Notice that in order for regulation to force banks to smooth their dividend stream, it is not enough to provide a deposit insurance mechanism. Competition among banks would lead to choose the maximum dividend and therefore banks will never build reserves, thus leading to a high probability of bankruptcy. In order to deal with this lack of incentives to create reserves, regulation will require the banks to make loss provisions which is equivalent in our model to restricting the dividend rules banks can choose. The same objective can be achieved by establishing minimum capital requirements for banks, thus allowing them to build the necessary capital buffer that limits the effect of competition and facilitates dividend smoothing.

\section{Accounting system}

In the previous section we have focussed on the role of banks as providers of intertemporal insurance and the key role of the dividend rule. We will now turn to examine the role of the accounting system.

A first remark is in order regarding the environments where accounting systems could be compared. If dividend rules are unrestricted, then accounting rules are irrelevant. This is obvious as nothing prevents the bank manager from ignoring its profits and paying the optimal dividend $D_{t}$. More precisely, if the bank's dividends are not affected by unrealized capital gains then there is no point in comparing book value and fair value accounting since this is the only difference between the two and dividend is the only channel in our simple framework through which this difference may affect consumption.

Therefore, we will assume both that unrealized capital gains affect dividends and that banks' dividends depend on accounting profits. This seems to be a natural assumption, which lies at the heart of the debate of book vs. fair value accounting which we will extensively use in our analysis. Nevertheless, keep in mind that our result would obtain if the banks' dividends were set as a function of, for instance, the bank's net income.

The dividend rule we consider, will therefore take the form

$$
D_{t}=\varphi\left(\pi_{t}\right)
$$

for an increasing function $\varphi$, where $\pi_{t}$ are the bank's profits. These profits will be different under book and fair value.

Under book value accounting the profits are $\pi_{t}^{B}=x_{t}^{B} y_{t}-r_{d} d$, whereas under fair value capital gains are taken into account, so that $\pi_{t}^{F}=x_{t}^{B} y_{t}-r_{d} d+$ $x_{t}^{B}\left(p_{t+1}-p_{t}\right)$. Thus, we have two dividend rules, $D_{t}=\varphi\left(\pi_{t}^{i}\right), i=B, F$.

Notice that we do not restrict dividends to be distributed only when profits are positive. 


\subsection{Welfare comparison}

From the perspective of allocative ex ante efficiency that we have adopted, the question that arises is simply which of these rules allows for a better intertemporal smoothing.

Of course, this may depend on the distribution of prices. Yet, the theory of efficient financial markets provide us with a natural property for the price distribution, and that is that prices follow a martingale, satisfying, $E\left(\widetilde{p_{t+1}} \mid\right.$ $\left.p_{t}\right)=p_{t}$, because given current available information, today's price is the best predictor of tomorrow's one. This assumption allow us to formulate the following proposition:

Proposition 2: If the market price of the bank's assets, $p_{t}$, follows a martingale then book value accounting Pareto dominates fair value accounting.

Proof. Since $E\left(p_{t+1}\right)=p_{t}$, and $p_{t+1}$ is independent of $y_{t}, \pi_{t}^{F}$ is a mean preserving spread of $\pi_{t}^{B}$. The corresponding consumption patterns are $c_{1 t}=$ $e_{t}-q_{t}$ and $c_{2 t}^{i}=q_{t+1}+D_{t}, i=B, F$. Therefore, $c_{2 t}^{F}$ is a mean preserving spread of $c_{2 t}^{B}$ and Lemma 3 applies.

The crucial insight of this proposition is that book value accounting facilitates intertemporal smoothing by allowing banks to smooth dividend distribution. On the other hand, fair value accounting, by accurately describing profits period by period precludes banks from transferring resources from the good states to the bad ones. Loosely speaking, book value accounting applies a multiperiod budget constraint to banks, whereas fair value obliges banks to satisfy period by period their budget constraint.

Notice that other price distributions may lead to the same result. In particular, when prices are i.i.d., since $E\left(p_{t+1}\right)=\mu$ is independent of $y_{t}, \pi_{t}^{F}$ is a mean preserving spread of $\pi_{t}^{B}$.

Remark that in the extreme case of an unlimited safety net, where the Treasury bears all the risks, the first best is attained and consumption is stationary providing consumers with full insurance against business cycle risk, $y_{t}$.

\subsection{Expected bankruptcy cost comparison}

It could be argued that the comparison between the two types of accounting rules need to consider welfare comparisons only. Indeed, it is sometimes a clearly stated mandate for the regulator, as in the case of the US, to minimize the expected costs of bank bankruptcies. For this reason, we now turn to this alternative perspective and focus on the regulators' minimization of bankruptcy costs. We study to what extent fair value accounting might reduce the expected cost of bankruptcy. If this is the case, a cost minimizing regulator would favour fair value accounting over book value accounting.

In order to analyse this point, we will assume the cost of bankruptcy is increasing in the bank's LGD (loss-given-default). LGD measures the extent of a bank's default at time $t+1$ and equals the difference between liabilities and 
assets, that is:

$$
L=\operatorname{Max}\left(0, d_{t}\left(1+r_{d}\right)-\left(M_{t}+x_{t}^{B}\left(p_{t+1}+y_{t}\right)\right)\right.
$$

Note that this cost depends upon the price of the asset $p_{t+1}$ but not on the accounting rule that is chosen. Consequently, the cost of bankruptcy is independent of the accounting system chosen since the actual default is measured at current market values.

The difference in the expected cost of bankruptcy stems from the different probabilities of bankruptcy depending on which accounting system we employ to characterize the onset of bankruptcy. This is the case as bankruptcy under book value is defined by the book value of assets being lower than the book value of liabilities. That is,

$$
M_{t}+x_{t}^{B}\left(p_{0}+y_{t}\right)<d_{t}\left(1+r_{d}\right)
$$

where $p_{0}$ reflects the historical value of the $\operatorname{assets}^{7}$.

The fair value definition of bankruptcy is given instead by

$$
M_{t}+x_{t}^{B}\left(p_{t+1}+y_{t}\right)<d_{t}\left(1+r_{d}\right)
$$

From these two inequalities we are able to compute the bankruptcy probabilities for both book and fair value accounting.

The probability of bankruptcy at time $t$ will be given by the value of equity, which in the fair value case equals $E_{t}^{F}=M_{t}+x^{B}\left(p_{t+1}+y_{t}\right)-d_{t}\left(1+r_{d}\right)$. Let $M_{\tau}=M_{\tau-1}+x^{B} y_{\tau-1}-r_{d} d_{t}-D_{\tau-1}$. By substituting recursively this expression, taking into account $M_{0}=0$ and $E_{0}+d_{t}=x_{t}^{B} p_{0}$, it is easy to compute $E_{t}^{F}$ as the result of the series of $y_{t}$ and of the policy dividend $D_{t}$. This yields

$$
E_{t}^{F}=E_{0}+\sum_{\tau=0}^{\tau=t}\left(x_{t}^{B} y_{\tau}-\left(D_{\tau}+d_{t} r_{d}\right)+x_{t}^{B}\left(p_{\tau+1}-p_{0}\right)\right)
$$

for the fair value case, which simply corresponds to the process of capital accumulation over time.

On the other hand, for the book value case where capital gains are not taken into account the previous expression simplifies to $E_{t}^{F}=E_{0}^{B}+\sum_{\tau=0}^{\tau=t}\left(x_{t}^{B} y_{t}-\right.$ $\left.\left(D_{t}+d_{t} r_{d}\right)\right)$, and capital gains $x_{t}^{B}\left(p_{\tau+1}-p_{0}\right)$ are disregarded.

In order to compare these two expressions, we have to answer the question of whether the dividend distribution policy differs between fair and book value.

\footnotetext{
${ }^{7}$ It is possible to argue that even if we consider book value accounting, the market may impose the closure of a bank when the market value of its assets becomes lower than the market value of its liabilities, despite the fact that the bank is solvent from a book value perspective. In this case, the accounting rule for bankruptcy coincides for the two accounting schemes. This in turn implies that the expected cost of bankruptcy is the same for the two accounting systems.
} 
Indeed, in the absence of any assumption on dividend policy it is impossible to infer anything from the above expression. Fortunately, there is a quite natural assumption to make, and that is that dividends are the same increasing function of current profits.

$$
D_{\tau}^{F}=\varphi\left(\pi_{t}^{B}, y_{t}\right) \text { and } D_{\tau}^{B}=\varphi\left(\pi_{t}^{B}, y_{t}\right) \text { with } \frac{d \varphi}{d \pi_{t}} \geq 0
$$

This is a natural assumption in the present context, because it assumes the same behavior on behalf of the managers, except for the choice of book vs. fair accounting system. Notice, that the extreme case where dividend distribution does not depend upon the accounting system, where $\varphi\left(\pi_{t}^{B}, y_{t}\right)=\phi\left(y_{t}\right)$ is also covered by our analysis.

Under the above assumption, if $p_{t}$ follows a martingale, then $E_{t}^{F}$ is a mean preserving spread of $E_{t}^{B}$. To see why, notice, first that the dividend $D_{\tau}^{F}$ is a mean preserving spread of $D_{\tau}^{B}$ for any $\tau$. Second, the value of equity under fair value accounting, $E_{t}^{F}$, includes the random term $x_{t}^{B}\left(p_{\tau+1}-p_{0}\right)$.

This implies that the probability of bankruptcy is higher under fair value accounting than under book value accounting.

Of course, the above conclusion has to be revised if, instead of following a martingale, asset prices are i.i.d, as we assumed in section 2, so that $E\left(p_{t}\right)=\gamma$. In that case, we would observe mean reversion, and depending on the initial price, we would have $E\left(p_{\tau+1}-p_{0}\right)=\gamma-p_{0}$ either positive or negative. If $\gamma-p_{0}=0$, then our argument carries over and $E_{t}^{F}$ is a mean preserving spread of $E_{t}^{B}$. Nevertheless, when asset prices are initially low, $\left(\gamma-p_{0}>0\right)$ this term decreases the probability of a bankruptcy under fair value accounting. This is quite intuitive and directly related to our definition of bankruptcy: when the bank has a high probability of obtaining capital gains in the future, its probability of a bankruptcy is decreased if capital gains are part of its profits and accumulated to its capital. It is then unclear which of the two effects, mean preserving spread versus undervalued assets will prevail. Conversely, if initially asset prices are high, so that $\gamma-p_{0}$ is negative, the probability of bankruptcy is larger under a fair value accounting system, as the two effects go in the same direction. Namely, not only is the distribution of $E_{t}^{F}$ "more risky", but it also has a lower expected value.

The existence of two cases, low initial prices and high initial prices, sheds light on the issue on the debate on reserves in the sixties, mentioned in the introduction. If $p_{0}$ is low $\left(\gamma-p_{0}>0\right)$ the bank has accumulated reserves and this favours book value accounting; however, if $\left(\gamma-p_{0}<0\right)$ the bank has negative reserves or non-disclosed losses, and this goes against the use of book value accounting.

\section{Fair value accounting, transparency and mar- ket discipline}

Since the debate on book vs. fair value accounting has emphasized the positive role of fair value accounting in disciplining banks, we would like to discuss this 
issue more extensively here using the insights of our model as a background.

The market discipline enhances efficiency because it leads to the elimination of the lame ducks. In the present context, this means that if under fair value accounting a bank's capital is below the minimum required by regulation, investors will not lend to the bank and this will forced it to close down. Notice that market discipline could also have been implemented by the bank regulator if the regulators deemed that the cost of forbearance was too high. Closing down an insolvent bank is efficient for several reasons. First, as for any firm, it redistributes the bankrupt resources to the surviving banks. Second, it limits the cost of bankruptcy, a point particularly sensitive for banks, as closing down a bank when its capital is still positive is less costly than closing it down when it is bankrupt. Third, as the bank closure is declared in the early stages, it limits the possibility for the bank to "gamble for resurrection" .

The conditions for market discipline to operate are those of imperfect information, where investor would not be able to assess the real value of the bank under book value but would be able to do so under fair value. Notice that we could complement book value accounting with the disclosure of the banks fair value of assets and liabilities. In this way, investors could enforce market discipline via their investment decisions. This would combine the virtues of book value accounting as related to intertemporal smoothing with those of allowing investor to discipline inefficient bank strategies.

It should be noted that (imperfect) market discipline may generate a type 1 error by penalizing a bank that is affected by a sudden liquidity undersupply whereas book value accounting may lead to a type 2 error by not detecting promptly an insolvent bank.

However, increased transparency and the subsequent market discipline induced by investors behavior also affects banks portfolio choice. Rational bank managers who expect a temporary adverse shock may act in an overly conservative manner ${ }^{9}$. In particular, they may choose either not to invest in risky assets or to reduce deposit interest rates, or opt not to distribute dividends. Thus ill-fortune and not managerial mismanagement may lead to portfolio choices that provide no intertemporal smoothing whatsoever, and consequently result in equilibrium allocations that are ex ante inefficient. The upshot of the argument is that fair value accounting via increased transparency and the consequent market discipline induced by risk-averse investors (or through regulatory intervention) reveals the classic trade-off between intra and intertemporal efficiency. Fair value accounting increases market discipline and this increases intratemporal efficiency. Yet, at the same time fair value accounting reduces intertemporal

\footnotetext{
${ }^{8}$ These two aspects were perfectly illustrated in the US S\&L crisis in the 1980s. A large fraction of the cost of the crisis was due to forbearance. Nevertheless, another fraction of the cost was due to the investment in high risk real state development projects outside the area of competence of the banks. This we interpret as "gambling for resurrection".

${ }^{9}$ Implicit to this argument is the assumption of incompleteness regarding executive compensation contrats. If the optimal compensation scheme is not available, then managers would not invest in their shareholders best interest. The effect of book vs. fair value accounting on managers compensation is a relevant but complex issue that has not been addressed so far in the literature and is beyond the scope of our paper.
} 
efficiency by limiting intertemporal smoothing.

So, to summarize, the introduction of the positive effects of market discipline lead us to a trade-off between intertemporal smoothing and the efficiency of the banking closure that could be attained through market discipline. Fair value accounting and the resulting market discipline increases the intratemporal efficiency of the banking system while book value accounting leads to intertemporal efficiency. Finally, given incomplete markets and the fact that equilibria are "typically" constrained inefficient (see Geanakoplos and Polemarchakis (1986)), increased risk taking with its ensuing LGD may improve welfare. On the one hand, banks improve intertemporal smoothing, thus economic efficiency, but on the other hand, may generate a deadweight loss due to banks failure.

\section{Concluding remarks and extensions}

Our analysis points to the direction of concrete policy implications. First, banks act as intergenerational connectors generating ex ante welfare improvements via intertemporal smoothing. No agent or an institution that is finitely lived can substitute this banking activity. For example, neither financial markets nor mutual funds can implement equilibrium allocations resulting from intertemporal smoothing. However, the implementation of banks as intergenerational connectors requires regulatory intervention. Some form of safety net such as deposit insurance is necessary when the banking sector faces repeated adverse shocks. Absence any type of safety net, any attempt by banks to smooth intertemporal consumption would result in a higher volatility of banks equity prices, thus leaving the equilibrium allocation unchanged, as it happens in a finite horizon environment.

Second, within the class of linear profit dependent dividend rules, book value accounting dominates fair value accounting in financial reporting. This is the case because book value accounting allows for better intertemporal smoothing than fair value. The reason behind this difference lies in the fact that book value accounting is a mean preserving 'shrink' over fair value accounting, and therefore, it enables the banking sector via dividends to smoothen intertemporal consumption of its shareholders.

From a regulatory point of view, book value accounting minimizes expected costs of bankruptcy industry. This is the case either when asset prices follow a martingale or when they are falling relative to their initial values. The key intuition behind this result is that both the probability of bankruptcy increases when asset prices fall and also fair value accounting is mean preserving spread of book value accounting thus reducing the expected value of equity. Both of these effects reinforce each other and they result into higher bankruptcy costs under fair value accounting.

Finally, the case in favour of the cited view that fair value accounting alone improves the efficiency of the banking industry by increasing transparency may be overstated. In our framework it is not always true that increased transparency allows market discipline to improve efficiency by reducing the riskiness 
of an insolvent bank's portfolio. Indeed, market discipline may very well introduce artificial volatility into earnings reports, and thereby preclude smooth dividend rules that provide investors with ex ante efficient intertemporal insurance.

Our framework provides a foundation for analyzing dynamic financial intermediation. However, certain characteristics of banking that are absent at this stage can easily be incorporated into it. The issue of moral hazard is abstracted away since we assume no split between ownership and control of banks. The rich literature of moral hazard in banking (see Freixas and Rochet (1997)) can be readily embedded into the model. Second, in order to address more succinctly transparency and market discipline with respect to associated accounting rules, one needs to formally introduce active and heterogeneous banks. This can be achieved using the model of Tsomocos (2003) which is compatible with the present one. Finally, one needs to examine a wider class of dividend rules than the ones we have considered here and investigate their welfare properties.

We view this paper as a first step towards modelling dynamic financial intermediation. Incorporating into our framework the aforementioned extensions would allow us to address rigorously the trade off between systemic risk and the possibility of contagion vs. the efficiency gains due to intertemporal smoothing that book value financial reporting possesses.

\section{Mathematical Appendix.}

\section{Proof. Proof. of Lemma 1:}

Assume there is a finite period $T$. Then, the bank is redundant because the Modigliani-Miller theorem applies and prices will adjust so as to reflect the value of the assets the bank holds.

Assume the bank holds $M_{T-1}$ in cash and $x^{B}$ of the stock. At time $T$ the banks assets are $M_{T}=M_{T-1}+y_{t} x^{B}$ in cash and its holding of the stock are unchanged. Since the value of the bank is distributed among its equity holder, its value will be $q_{T}+D_{T}=M_{T-1}+\left(p_{T}+y_{T}\right) x^{B}$ and return on the bank stock will be $r_{s, T-1}=\frac{q_{T}+D_{t}}{q_{T-1}}=\frac{M_{T-1}+\left(p_{T}+y_{T}\right) x^{B}}{q_{T-1}}$. This implies that a portfolio of $\left(M_{T-1}, x^{B}\right)$ will generate exactly the same contingent return and the price of the bank has to equal the price of the portfolio: $q_{T-1}=M_{T-1}+p_{T-1} x^{B}$

Proceeding by backwards induction, assume that the equality $q_{t}=M_{t}+p_{t} x^{B}$ holds for $t$ and let us proceed to prove that it has to hold for $t-1$. The proof is the same as above, with the difference that the distributed dividend may now differ from the $y_{t} x^{B}$. The difference $y_{t} x^{B}-D_{t}$ will be added (subtracted) to the bank cash holding, so that $M_{t}=M_{t-1}+y_{t} x^{B}-D_{t}$. But once we compute the net return, the dividend cancels out. $r_{s, t-1}=\frac{q_{t}+D_{t}}{q_{t-1}}=\frac{M_{t}+p_{t} x^{B}+D_{t}}{q_{t-1}}=$ $\frac{M_{t-1}+y_{t} x^{B}+p_{t} x^{B}}{q_{t-1}}$ so that the value of the bank equals the value of a portfolio with a holding of $M_{t-1}$ of cash and $x^{B}$ of shares. 


\section{References}

Aghion, P., Bolton, P. and S. Fries (1999), "Optimal Design of Bank Bailouts: The Case of Transition Economies", Journal of Institutional and Theoretical Economics 155, 51-70.

Allen F. and D. Gale (1997), "Financial Markets, Intermediaries, and Intertemporal Smoothing", Journal of Political Economy, vol. 105, n. 3:523-46.

Basel Committee on Banking Supervision (1997), "Core Principles for Effective Banking Supervision". Basel, September.

Bhattacharya, S., Fulghieri, P. and R. Rovelli (1998), "Financial Intermediation Versus Stock Markets in a Dynamic Intertemporal Model", Journal of Institutional and Theoretical Economics, vol. 154:291-324.

Bloise, G. and H.M. Polemarchakis (2004) "Intertemporal Optimality", mimeo, Brown University.

Chisnall, P. (2000), "Fair Value Accounting: an industry view", British Bankers' Association, 2000.

Diamond, D. and P. Dybvig (1983), "Bank Runs, Deposit Insurance, and Liquidity", Journal of Political Economy, 91:401-419.

Enria et al. (2004), "Fair Value Accounting and Financial Stability", ECB Occasional Paper, 13, April 2004.

Freixas and Rochet (1987) "Microeconomics of Banking". MIT Press, Cambridge, Massachussets.

Geanakoplos, J.D. and H.M. Polemarchakis (1986) "Existence, Regularity and Constrained Suboptimality of Competitive Allocations When the Asset Market is Incomplete", in: Heller, W., Starret, D. (Eds), Essays in Honor of K. Arrow, Vol. III. Cambridge University Press, Cambridge, U.K.

Goodhart, C.A.E., (1972) "The Business of Banking: 1891-1914", London: Weidenfeld and Nicolson.

Gorton, G. and G. Pennacchi (1990), "Financial Intermediaries and Liquidity Creation", Journal of Finance 45, No. 1, March 1990.

Jackson, P. and D. Lodge, (2000), "Fair value accounting, capital standards, expected loss provisioning, and financial stability", Financial Stability Review, Bank of England.

Qi, Jianping (1994) "Bank Liquidity and Stability in an Overlapping Generations Model", The Review of Financial Studies, vol. 7, n. 2, pp. 389-417.

Samuelson, P.A., (1958) "An Exact Consumption-loan Model of Interest Without the Social Contrivance of Money", Journal of Political Economy, 66:46782.

The Economist (1901), p. 204

Tsomocos (2003), "Equilibrium Analysis, Banking an Financial Instability", Journal of Mathematical Economics, 39:619:655. 